\title{
Luminescent Blinking from Silver Nanostructures
}

\author{
Chris D. Geddes, ${ }^{\dagger}$ Alex Parfenov, ${ }^{\ddagger}$ Ignacy Gryczynski, ${ }^{\dagger}$ and Joseph R. Lakowicz $*$ \\ Institute of Fluorescence and the Center for Fluorescence Spectroscopy, Medical Biotechnology Center, \\ University of Maryland Biotechnology Institute, 725 West Lombard Street, Baltimore, Maryland 21201, and \\ Center for Fluorescence Spectroscopy, Department of Biochemistry and Molecular Biology, \\ University of Maryland at Baltimore, 725 West Lombard Street, Baltimore, Maryland 21201
}

Received: February 28, 2003; In Final Form: June 2, 2003

\begin{abstract}
Silver nanostructures deposited on glass showed luminescent blinking when excited at a high 442 nm irradiance. The irradiance required to photoactivate the silver, was dependent on the nature of the silver nanostructures. Silver fractal-like structures were found to be highly emissive, requiring only $\approx 30 \mathrm{~W} / \mathrm{cm}^{2}$ for photoactivation as compared to silver island films and spin-coated silver colloids, which required a significantly higher irradiance, $>100 \mathrm{~W} / \mathrm{cm}^{2}$, to observe similar luminescent emission. In contrast to our recent findings for gold colloids, foci with different color blinking were also observed, with an increase in luminescence intensity as a function of time. We place these findings in context with recent work from our laboratory which employs these silver nanostructures for applications in metal-enhanced fluorescence, a relatively new phenomenon in fluorescence, whereby metallic particles, colloids, and fractal-like structures can modify the intrinsic radiative decay rate of close proximity fluorescent species. These effects are a consequence of localized changes in photonic mode density around the fluorophores, and we can now report are typically observed at significantly lower illumination intensities as compared to those required to photoactivate silver. Subsequently, our findings strongly suggest that the enhanced fluorescence emission of fluorophores positioned in close proximity to metallic silver structures is not due to either intrinsic silver blinking, or indeed the silver luminescence pumping the fluorophore. Further, the intrinsic luminescence properties of silver reported here, suggest a new class of luminescence probes and labels.
\end{abstract}

\section{Introduction}

There is a growing literature on the optical and electronic properties and uses of silver nanostructures, particularly silver colloids. ${ }^{1,2}$ These display bright colors due to the plasmon absorption, which is due to a combination of both absorption and scatter., ${ }^{3,4}$ One particular use of the enhanced electromagnetic fields close to the metal-medium interface has allowed for SERS, surface-enhanced raman scattering, to become a discipline in its own right. For single rhodamine $6 \mathrm{G}$ molecules adsorbed on selected nanoparticles, individual molecule Raman signatures can be observed, with Raman enhancement factors of $10^{14}$ to $10^{15} \cdot 5^{5-7}$ This enormous enhancement leads to vibrational Raman signals that are more intense and more stable than single molecule-fluorescence. The control of the nanoscale optical properties of silver nanostructures has also led to nanophotonic devices ranging from nanosensors ${ }^{8}$ to waveguides, ${ }^{9}$ as well as in a wide variety of applications in biotechnology. ${ }^{10-14}$ Several recent publications have also reported luminescence from these silver nanoparticles, in particular silver oxide particles, with envisaged applications in optical storage. ${ }^{15}$ Recent microscopy studies of nanoscale silver oxide reveals strong photoactivated emission for excitation wavelengths shorter than $520 \mathrm{~nm}$, with multicolor blinking, even from single nanoparticles. The individual luminescent species are thought to be silver nanostructures that are photochemically generated from the oxide, ${ }^{15}$ where the several Ag atom nanoclusters show a strongly size-dependent luminescence. ${ }^{16}$

* All correspondence: lakowicz@cfs.umbi.umd.edu.

University of Maryland Biotechnology Institute.

$\div$ University of Maryland at Baltimore.
In this paper we report the luminescent blinking of other silver nanostructures, in particular, silver island films, silver colloids, and silver fractal-like structures. These structures are deposited or grown on glass microscope cover slips. In addition to studying their luminescent blinking properties for potential applications as luminescent probes, as markers, and for medical imaging, our primary interest lies in their interactions with organic fluorophores, and how they modify fluorophore spectral properties. The favorable effects produced by close proximity fluorophores to metallic nanostructures includes increased quantum yields and reduced lifetimes, ${ }^{13,14,17,18}$ increased fluorophore photostability, ${ }^{13,14,19,20}$ enhanced multiphoton excitation, ${ }^{21,22}$ and modified rates of energy transfer. ${ }^{23-25}$ These interactions have been described as due to changes in the photonic mode density, PMD, around the fluorophore, ${ }^{26}$ and are considered to be through-space as compared to SERS, which is widely thought to be a contact interaction. ${ }^{27,28}$ Such effects are not normally observed in bulk media, where the photonic mode density is not that different from a vacuum, but can be changed by close proximity silver nanostructures. ${ }^{26} \mathrm{We}$ have recently referred to this phenomenon as radiative decay engineering (RDE), ${ }^{13,14,26}$ because we were primarily interested in changes in the radiative decay rate, which results in more detectable photons from fluorophores, but occasionally we use the term "metal-enhanced fluorescence" which additionally accounts for another favorable metal-induced effect, namely increased rates of excitation. ${ }^{17}$

Here we report the luminescent blinking of the silver nanostructures that we have previously employed in MEF. However, these previous MEF studies were achieved using irradiances significantly smaller than those used to observe the 


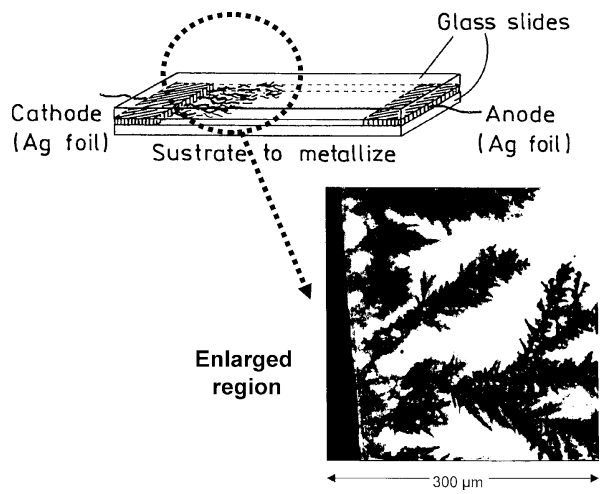

Figure 1. Apparatus for silver fractal growth and the bright field image of the silver fractal-like structures grown on glass.

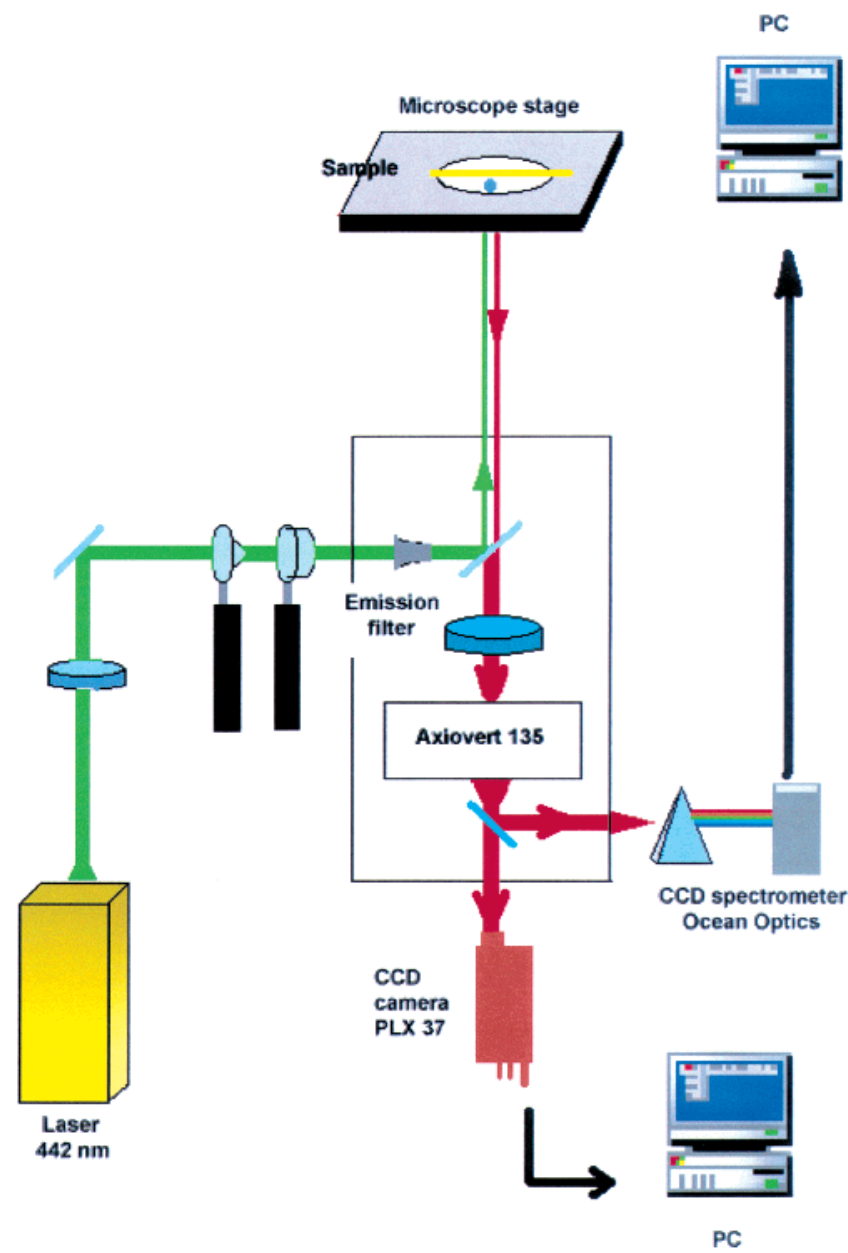

Figure 2. Apparatus for the observation of luminescent blinking from silver nanostructures.

nanostructure luminescence reported here. Our results show that these nanostructures show a time-dependent activation and subsequent luminescent blinking, with multicolor blinking, differing in both intensity and location, also dependent on the type of structure and irradiance used. We observed that the silver fractal-like structures were highly emissive and could be photoactivated at a much lower irradiance, typically $>30 \mathrm{~W} / \mathrm{cm}^{2}$, as compared to glass-coated silver island films and colloids, where silver island films were found to be the least emissive under similar experimental conditions. Our results show that the luminescent blinking of silver nanostructures occurs at a much higher irradiance (over 1000-fold) than is currently employed in, or is practical, for applications of MEF, strongly suggesting the important and unrecognized notion that MEF is
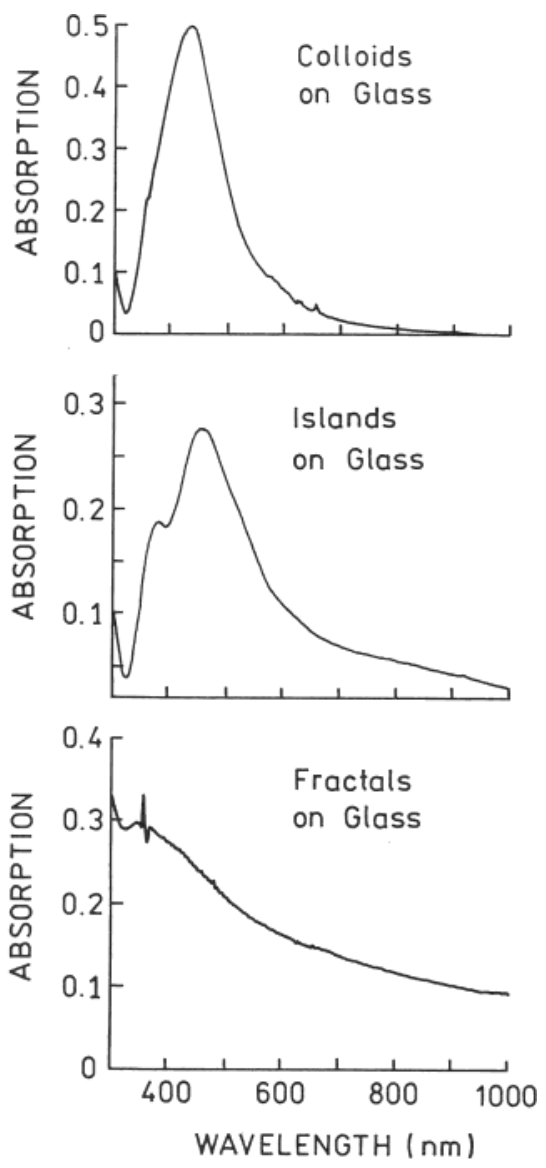

Figure 3. Absorption spectrum of spin-coated silver colloids on glass (top), silver island films, $\mathrm{SiFs}$ (middle), and silver fractal-like structures grown on glass (bottom).

not a consequence of underlying intrinsic silver luminescence. These results therefore suggest that the luminescent blinking properties of silver could be utilized to identify and locate silver depositions, for low laser power biotechnology applications of MEF. Indeed, we have recently reported that the photodeposition of silver from a silver colloid solution with laser light illumination $\left(442 \mathrm{~nm}, 560 \mathrm{~W} / \mathrm{cm}^{2}\right)$, resulted in localized silver depositions that could be used for applications of MEF. ${ }^{29}$

\section{Materials and Methods}

The silver nanostructures were coated/grown on cleaned microscope cover slips (Fisher Scientific). The cover slips were initially cleaned by immersion in $30 \% \mathrm{v} / \mathrm{v} \mathrm{H}_{2} \mathrm{O}_{2}$ and $70 \% \mathrm{v} / \mathrm{v}$ $\mathrm{H}_{2} \mathrm{SO}_{4}$ for $48 \mathrm{~h}$ and then washed in distilled water.

Fractal-like silver structures were grown on glass using two silver electrodes held between two glass microscope cover slips, Figure 1 . The electrodes were $10 \times 35 \times 0.1 \mathrm{~mm}$, with about $20 \mathrm{~mm}$ between the two electrodes. Deionized water was placed between the slides. A direct current of $10 \mu \mathrm{A}$ was passed between the electrodes for about $10 \mathrm{~min}$, during which the voltage started near $5 \mathrm{~V}$ and decreased to $2 \mathrm{~V}$. During the current flow, fractal silver structures grew on the cathode and then on the glass near the cathode, Figure 1. The fractal-like structures grew rapidly but appeared to twist as they grew. These structures are similar to those reported recently during the electroplating of insulators. ${ }^{30}$ Bright field images were obtained with a Roper RLX-37 CCD camera.

Silver colloids were formed by the reduction of a warmed solution of silver nitrate by sodium citrate. This procedure is reported to yield homogeneously sized colloids near $20-30 \mathrm{~nm}$ 

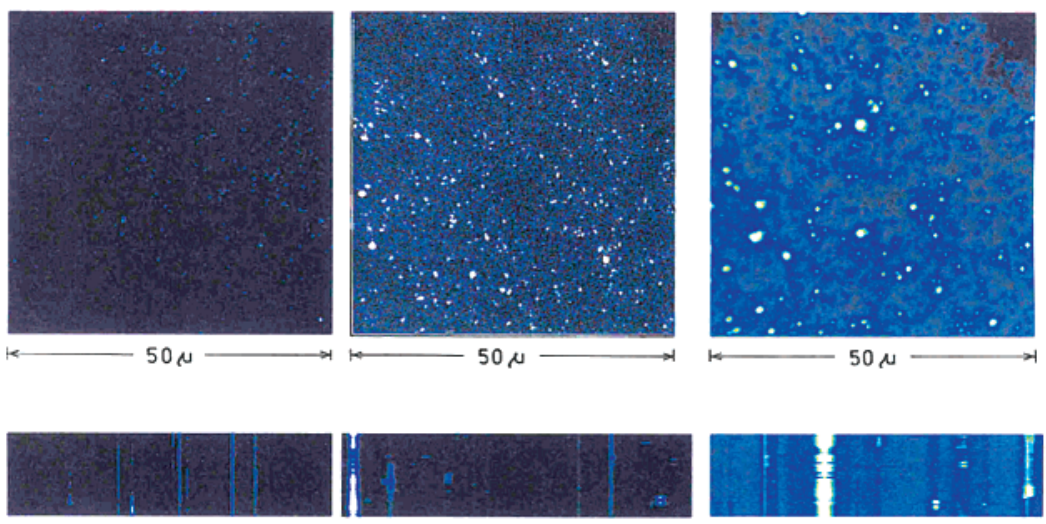

A

B

C

Figure 4. Representative luminescence images of silver nanostructures on glass: (A) silver island films; (B) silver colloid coated glass; (C) silver fractal coated glass. Nanostructure luminescence was observed using a standard epifluorescence geometry using an Axiovert 135 TV inverted microscope with $442 \mathrm{~nm} \mathrm{HeCd} 200 \mathrm{~W} / \mathrm{cm}^{2}$ excitation. For these images a water-immersion objective $(40 \times 1.2 \mathrm{NA})$ was used. Also shown (bottom) are compiled frames $(200 \mathrm{~ms} /$ frame), which show the luminescent blinking of the silver nanostructures.

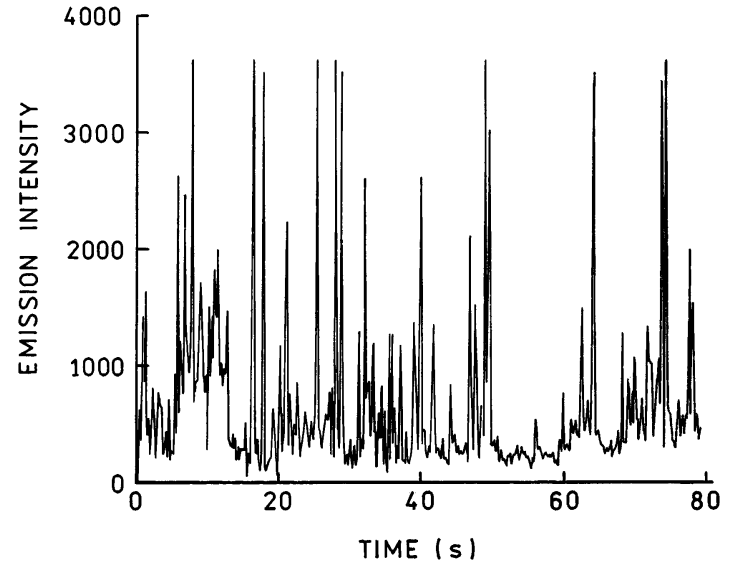

Figure 5. Time-dependent luminescent blinking observed from a randomly selected silver fractal luminescent spot. The $442 \mathrm{~nm}$ excitation intensity was $200 \mathrm{~W} / \mathrm{cm}^{2}$. The typical single-particle blinking traces were acquired for 400 frames with a $200 \mathrm{~ms}$ time resolution.

in diameter. ${ }^{31,32}$ The silver colloids were spin cast on a cleaned microscope cover slip (Fisher Scientific). Typically, $50 \mu \mathrm{L}$ of silver colloid solution (undiluted) was dropped onto a glass microscope slide and spin-coated at $3000 \mathrm{rpm}$ for $30 \mathrm{~s}$. The resultant silver colloid film was then allowed to dry in air for $\approx 2$ min and then used.

Silver island films were formed on glass microscope cover slips according to published procedures ${ }^{33}$ and as modified in

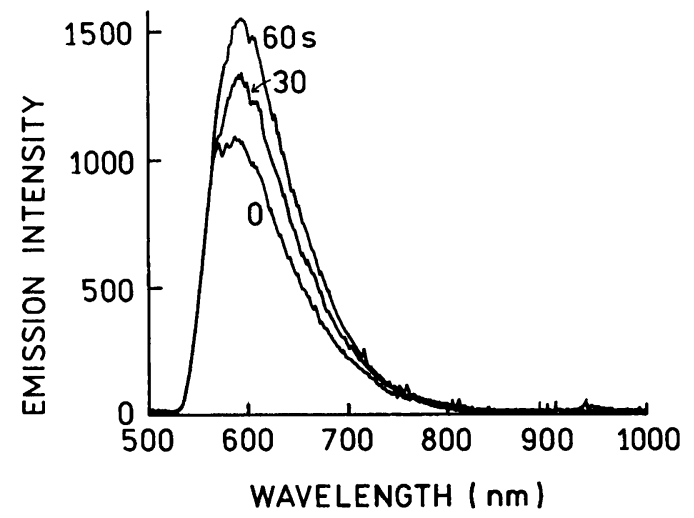

our recent reports. ${ }^{14}$ The deposition procedure consists of reducing silver nitrate with D-glucose under controlled conditions. ${ }^{14}$ This procedure results in a partial coating of the glass with silver islands. The diameters of the islands are typically from 100 to $500 \mathrm{~nm}$ across and near $60 \mathrm{~nm}$ high, with some aggregates. ${ }^{14}$ These particles display a characteristic surface plasmon resonance with a maximum near $480 \mathrm{~nm}$ and with an optical density near 0.3 . Absorption measurements were taken on a Varian UV/vis 50 spectrophotometer for all silvered glass slides.

The silver-coated slides were examined using the apparatus in Figure 2. The samples were illuminated with $20-500 \mathrm{~W} / \mathrm{cm}^{2}$ of $442 \mathrm{~nm}$ light from a HeCd laser. This light was incident on the back of a PlanNEofluor objective, either NA $=1.3, \times 100$, or NA $=1.2, \times 40$. Emission was observed in the epifluorescence mode using an Axiovert 135 TV Zeiss microscope. The emission was isolated from Rayleigh and Raman-shifted light by a combination of filters, a laser line filter 532NB3, a dichoric filter 570 DLPP and an emission filter 605DF50 (Omega Optical, Inc). Images were acquired using a cooled 12-bit highspeed CCD camera, PLX-37, Photometrics, and stored on a PC using $\mathrm{V}^{2+}$ software from Digital Optics, Ltd.

\section{Results and Discussion}

Figure 3 shows the absorption spectrum of the silver colloids on glass (top), silver island film coated glass (middle) and silver fractals on glass (bottom). The absorption spectrum of the

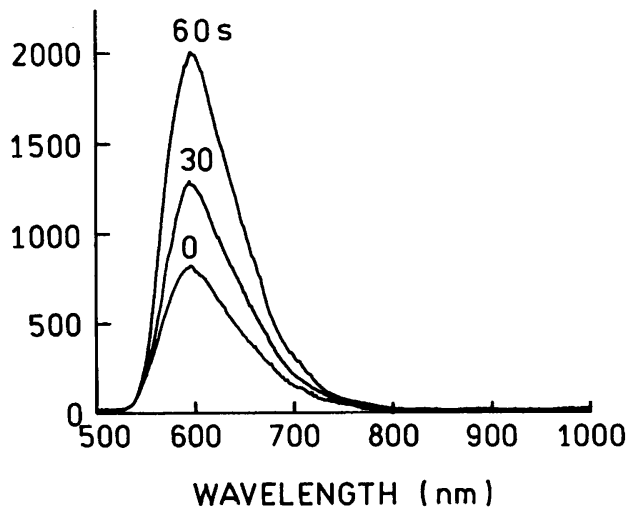

Figure 6. Luminescence spectra from silver colloids (left) and from silver fractal coated glass (right), showing time-dependent photoactivation (luminescence). Excitation was from a $442 \mathrm{~nm} \mathrm{He}-\mathrm{Cd}$ laser, ca. $200 \mathrm{~W} / \mathrm{cm}^{2}$, and luminescence was collected as shown in Figure 2. 
fractals on glass is broader than the silver islands films and colloids on glass respectively, where the silver fractals can be seen to have a more significant red absorption than the islands or colloids. This supports current literature in that elongated silver nanoparticles have a pronounced red-shifted surface plasmon absorption, ${ }^{13}$ although to the best of our knowledge there are no other reports of the plasmon absorption of silver fractal-like structures.

The silver nanostructures on glass were observed visually upon illumination at $442 \mathrm{~nm}$. At the onset of illumination, there was a rapid appearance of many highly emissive spots (for all structures). The number of spots increased for about a second and then remained constant. Most of the spots displayed blinking that persisted over many minutes of observation (Figure 4). Some spots appeared to change color as a function of time but did not photobleach. This is in contrast to our recent studies of spin-coated gold colloids, which did not change color but also blinked, and which required a significantly higher irradiance to observe any luminescence (typically $\mathrm{kW} / \mathrm{cm}^{2}$ ). ${ }^{34}$

We generally found that the silver fractal surfaces photoactivated (luminesced) at much lower irradiances $\left(>30 \mathrm{~W} / \mathrm{cm}^{2}\right)$, as compared to both the colloid and silver island film coated glass $\left(>100 \mathrm{~W} / \mathrm{cm}^{2}\right)$. Figure 4 shows representative luminescence images from the three surfaces when irradiated with 442 $\mathrm{nm}\left(200 \mathrm{~W} / \mathrm{cm}^{2}\right)$ laser light, using the instrumentation in Figure 2. At this constant irradiance we observed significantly more emission from the fractal coated glass (C) as compared to the SiF-coated glass (A). Much more of the silver fractal surface was luminescent, with some areas showing very bright luminescence indeed. We found that the irradiance required to photoactivate the surfaces varied between sample preparations, but generally followed the trend: Fractals were easier than colloid surfaces, which were easier than SiF surfaces to photoactivate.

Figure 4 (bottom) shows a typical blinking trace from the above silver nanostructure luminescence images. The images are read from top to bottom, where 400 images, across one random line, were taken $200 \mathrm{~ms}$ apart. We can clearly see the time-dependent blinking behavior of the structures, with some silver structures constantly luminescent and others blinking. This blinking behavior is comparable to that typically found for single molecule fluorescence, with the possibility here of more than one emissive foci in the given $50 \mu \mathrm{m}$ spot size. Similar blinking was also seen for other selected fractal luminescent spots, Figure 5 , where again the $50 \mu \mathrm{m}$ spot size allows for the possibility of multiple luminescent blinking foci. Interestingly, Figure 5 also serves to give an indication of the relative blinking intensities observed.

Figure 6 shows the emission spectra of silver colloids spincoated on glass cover slips (left) and from silver fractal coated glass (right). Essentially the same emission spectra were recovered from each spot, i.e., the $50 \mu \mathrm{m}$ spot shown in Figure 4, panels B and C. Interestingly, the luminescence intensities increased during the first minute but became constant after several minutes (not shown). Also, multicolor blinking was observed during this period, yet the average emission spectra typically remained the same shape, with an emission maxima of $\approx 600 \mathrm{~nm}$ observed from both silver structures. This was due to the fact that the foci of individual blinking spots were much smaller than the $50 \mu \mathrm{m}$ resolution of the instrument, and hence individual colors could not be resolved. Though not shown, the emission spectra of SiFs (Excitation $442 \mathrm{~nm} / 200 \mathrm{~W} / \mathrm{cm}^{2}$ ) were also centered at $\approx 600 \mathrm{~nm}$.

\section{Conclusions}

Silver nanostructures, used in recent studies for metalenhanced fluorescence, ${ }^{13,14,17-26,29,34}$ show blinking that is dependent on both the type of structure studied and irradiance of the illumination source. We typically observed that silver fractal-like structures could readily be made luminescent with irradiances of $30 \mathrm{~W} / \mathrm{cm}^{2}$ or more, as compared to silver island films, which required at least a 3-5-fold increase, $>100 \mathrm{~W} / \mathrm{cm}^{2}$. These values are somewhat arbitrary, and though for the most part were reproducible, were clearly dependent on the preparation of the silver surface. At the typical irradiances employed in MEF and $\operatorname{RDE}^{13,14,17-26,29,34}(\approx 1000$-fold lower), the silver surfaces can be considered essentially dark, with no silver luminescence observed. This important observation strongly supports the notion that MEF is not a consequence of underlying intrinsic silver luminescence.

Interestingly, the luminescent properties of both silver and gold colloid coated surfaces also appear to be different. ${ }^{34}$ First, much higher irradiances are required to observe gold colloid luminescence, typically $\mathrm{kW} / \mathrm{cm}^{2}$. Second, although gold colloids have been observed to blink, no changes in foci color were seen, which is in contrast to silver colloid coated surfaces. This suggests that silver structures may be preferable as labels or probes as compared to their gold counterparts.

Acknowledgment. This work was supported by the National Center for Research Resource, RR-08119 and the National Institute of Biomedical imaging and Bioengineering (NIBIB, EB-000682 and EB-000981). Partial salary support from UMBI for I.G. and J.R.L. is also gratefully acknowledged.

\section{References and Notes}

(1) Kreibig, U.; Vollmer, M.; Toennies, J. P. Optical Properties of Metal Clusters; Springer-Verlag: Berlin, 1995.

(2) Link, S.; El-Sayed, M. A. Int. Rev. Phys. Chem. 2000, 19, 409.

(3) Yguerabide, J.; Yguerabide, E. E. Anal. Biochem. 1998, 262, 137.

(4) Yguerabide, J.; Yguerabide, E. E. Anal. Biochem. 1998, 262, 157.

(5) Hildebrandt, P.; Stockburger, M. J. Phys Chem. B 1984, 88, 5935.

(6) Kneipp, K.; Wang, Y.; Kneipp, H.; Itzkan, L.; Dasari, R. R.; Feld, M. S. Phys. Rev. Lett. 1996, 76, 2444.

(7) Kneipp, K.; Wang, Y.; Kneipp, H.; Perelman, L. T.; Itzkan, L.; Dasari, R. R.; Feld, M. S. Phys. Rev. Lett. 1997, 78, 1667.

(8) Nalwa, H. S., Ed. Nanostructured materials and nanotechnology; Academic Press: New York, 2000

(9) Timp, G. Nanotechnology; Springer-Verlag: New York, 1999.

(10) Stich, N.; Gandhum, A.; Matushin, V.; Raats, J.; Mayer, C.; Alguel, Y.; Schalkhammer, T. J. Nanosci. Nanotechnol. 2002, 2 (3/4), 375.

(11) Stich, N.; Gandhum, A.; Matushin, V.; Mayer, C.; Bauer, G.; Schalkhammer, T. J. Nanosci. Nanotechnol. 2001, 1 (1), 397.

(12) Storhoff, J. J.; Elghanian, R.; Mucic, R. C.; Mirkin, C. A.; Letsinger, R. L. J. Am. Chem. Soc. 1998, 120, 1959.

(13) Lakowicz, J. R. Anal. Biochem. 2001, 298, 1-24

(14) Lakowicz, J. R.; Shen, Y.; D’Auria, S.; Malicka, J.; Fang, J.; Gryczynski, Z.; Gryczynski, I. Anal. Biochem. 2002, 301, 261.

(15) Peyser, L. A.; Vinson, A. E.; Bartko, A. P.; Dickson, R. M. Science 2001, 291, 103 .

(16) Peyser, L. A.; Lee, T.-H.; Dickson, R. M. J. Phys. Chem. B 2002, 106,7725 .

(17) Geddes, C. D. and Lakowicz, J. R. J. Fluorescence 2002, 12 (2), 121.

(18) Gryczynski, I.; Malicka, J.; Gryczynski, Z.; Geddes, C. D.; Lakowicz, J. R. J. Fluorescence 2002, 12 (1), 11.

(19) Geddes, C. D.; Cao, H.; Lakowicz, J. R. Spectrochim. Acta A, in press.

(20) Geddes, C. D.; Cao, H.; Gryczynski, I.; Gryczynski, Z.; Fang, J.; Lakowicz, J. R. J. Phys. Chem. A 2003, 107, 3443.

(21) Lakowicz, J. R.; Gryczynski, I.; Malicka, J.; Gryczynski, Z.; Geddes, C. D. J. Fluorescence 2002, 12 (3/4), 299.

(22) Gryczynski, I.; Malicka, J.; Shen, Y; Gryczynski, Z; Lakowicz, J. R. J. Phys. Chem. B 2002, 106 (9), 2191.

(23) Gryczynski, I.; Malicka, J.; Gryczynski, Z.; Lakowicz, J. R.; Geddes, C. D. J. Fluorescence 2002, 12 (2), 131. 
(24) Lakowicz, J. R.; Gryczynski, I.; Shen, Y. B.; Malicka, J.; Gryczynski, Z. Photonics Spectra 2001, 35 (10), 96.

(25) Malicka, J.; Gryczynski, I.; Fang, J.; Kusba, J.; Lakowicz, J. R. Anal. Biochem., in press.

(26) Lakowicz, J. R.; Malicka, J.; Gryczynski, I.; Gryczynski, Z.; Geddes, C. D. J. Phys. D 2003, 36, R240-R249.

(27) Fleischmann, M.; Hendra, P. J.; McQuillan, A. J. Chem. Phys. Lett. 1974, 26 (2), 163.

(28) Roth, E.; Hope, G. A.; Schweinsberg, D. P.; Kiefer, W.; Fredericks, P. M. Appl. Spectrosc. 1993, 47 (11), 1794.
(29) Geddes, C. D.; Parfenov, A.; Lakowicz, J. R. Appl. Spectrosc. 2003 , 57 (5), 526.

(30) Fleury, V.; Watters, W. A.; Allam, L.; Devers, T. Nature, 2002, $416,716$.

(31) Gersten, J. and Nitzan, A. J. Chem. Phys. 1981, 75 (3), 1139.

(32) Weitz, D. A.; Garoff, S. J. Chem. Phys. 1983, 78, 5324.

(33) Ni, F.; Cotton, T. M. Anal. Chem. 1986, 58, 3159.

(34) Geddes, C. D.; Parfenov, A.; Gryczynski, I.; Lakowicz, J. R. Chem. Phys. Lett., in press. 